\title{
Response surface methodology for the extraction of bioactive compound from black glutinous rice
}

\author{
${ }^{1 *}$ Penjumras, P., ${ }^{1}$ Wattananapakasem, I. ${ }^{2}$ Panjan, W., ${ }^{3}$ Panngom, K. and \\ ${ }^{2}$ Sornsakdanuphap, J. \\ ${ }^{1}$ Program of Food Technology, Maejo University-Phrae Campus, 54140 Rongkwang, Phrae, Thailand. \\ ${ }^{2}$ Program of Basic Science, Maejo University-Phrae Campus, 54140 Rongkwang, Phrae, Thailand. \\ ${ }^{3}$ Program of Applied Biology, Maejo University-Phrae Campus, 54140 Rongkwang, Phrae, Thailand.
}

\section{Article history: \\ Received: 19 April 2020 \\ Received in revised form: 8 \\ June 2020 \\ Accepted: 8 August 2020 \\ Available Online: 27 \\ December 2020}

\section{Keywords:}

Black glutinous rice,

Total phenolic content,

Antioxidant activity,

Solvent extraction,

Response surface

methodology

DOI:

https://doi.org/10.26656/fr.2017.4(S6).028

\begin{abstract}
This study was aimed at the extraction of total phenolic compounds, as well as, the antioxidant activity of black glutinous rice (Oryza sativa L.). Black glutinous rice of three varieties consists of Leum Pua, Doi Saket, and Phayao were extracted using citric acid solvent. The influences of temperature, time and $\mathrm{pH}$ value on total phenolic content and antioxidant activity (percentage of inhibition of DPPH free radical) were investigated. A central composite design was employed to determine the optimum extraction condition to obtain the highest total phenolic content and antioxidant activity. The regression models of total phenolic content were significant $(\mathrm{p} \leq 0.05)$ and determination coefficients values were $0.8028,0.8089$, and 0.8603 of Leum Pua, Doi Saket, and Phayao, respectively. The regression models of DPPH inhibition were significant $(\mathrm{p} \leq 0.05)$ and determination coefficients values were $0.8084,0.8928$, and 0.8243 of Leum Pua, Doi Saket, and Phayao, respectively. The selected optimum conditions were $72^{\circ} \mathrm{C}, 91 \mathrm{mins}$ at $\mathrm{pH} 1.44$ for Leum Pua, $72.5^{\circ} \mathrm{C}, 83$ mins at $\mathrm{pH} 1.39$ for Doi Saket, and $66.3^{\circ} \mathrm{C}, 75$ mins at $\mathrm{pH} 1.32$ for Phayao. Under the optimum condition, total phenolic content and percentage of inhibition of DPPH free radical of extract from Leum Pua, Doi Saket and Phayao were $0.3814 \mathrm{mg}$ GAE g ${ }^{-1}$ DW with $89.36 \%, 0.2607 \mathrm{mg} \mathrm{GAE} \mathrm{g}^{-1}$ DW with $73.33 \%$, and $0.2617 \mathrm{mg} \mathrm{GAE} \mathrm{g}^{-}$ ${ }^{1}$ DW with $75.27 \%$, respectively. The results showed that the total phenolic content of the extract indicated a highly positive correlation with antioxidant activity.
\end{abstract}

\section{Introduction}

Rice (Oryza sativa L.) is being consumed as a staple food for many countries nearly half of the world population, particularly in the Asian country. Rice can be classified by their colours which are white rice, brown rice, red rice and black rice. Nowadays, pigmented rice has been receiving more attention in commerce in Thailand due to the consumer trend of health awareness. Pigmented rice such as black rice, are good sources of basic nutrients, fiber, minerals and phytochemicals (Bae et al., 2017). In particular, pigmented rice varieties contain a higher amount of phenolic compound; cyanidin -3-glucoside, malvidin-3-glucose, and peonidin-3glucoside compare to white rice (Pedro et al., 2016; Bae et al., 2017; Seekhaw et al., 2018). The main anthocyanin is cyanidin-3-glucoside, meanwhile, peonidin-3-glucoside is the minor component (Chen et al., 2012). In this sense, anthocyanins extracted from plants may be suitable to be substituted instead of synthetic dyes because of their water solubility and bright color which allows them to be added into foods (Nontasan et al., 2012; Pedro et al., 2016). However, there is some limitation of extraction of phytochemicals, such as their chemical stability with respect to $\mathrm{pH}$, temperature and light (Pedro et al., 2016). For extraction of chemical component, the most commonly used solvents are methanol, ethanol, water acidified with an acidic solution. Ethanol and organic acids such as citric acid and acetic acid are desirable because they are less toxic than methanol and hydrochloric acid (EscribanoBailón et al., 2004; Phetpornpaisan et al., 2014; Shao et al., 2014). The factor such as type of solvent, extraction temperature, extraction time and the ratio of sample to solvent has a significant influence on the extraction process, therefore the combination of these factors and determination of optimal conditions are important in order to achieve a suitable yield of phenolic compound and its property. To overcome this limitation, the use of 
mathematical models that describe accurately the isolated and combined effects of different factors seem to be the most promising approach to obtain a functional extract from black rice. Response surface methodology (RSM) is a method used to develop and optimize processes and products (Pedro et al., 2016). Therefore, the effects of input variables (extraction temperature, time, and $\mathrm{pH}$ ) on total phenolic content and antioxidant activity (percentage of inhibition of DPPH free radical) were studied on contour plots. In addition, the optimized conditions of the independent variables to maximize values were also reported in this research.

\section{Materials and methods}

\subsection{Extraction of bioactive compound from black rice}

Black glutinous rice of three varieties consist of Leum Pua, Doi Saket and Phayao were purchased from a local market in northern Thailand. Response surface methodology (RSM) was used to optimize the conditions for the extraction of bioactive compound. The design of the experiment was done using Design Expert 12 (StatEase Inc, USA). Three independent variables were employed by central composite design (CCD). The variables used were extraction temperature $\left(\mathrm{X}_{1}\right)$, extraction time $\left(\mathrm{X}_{2}\right)$ and $\mathrm{pH}\left(\mathrm{X}_{3}\right)$. The design consisted of 20 runs including six axial experiments (levels $\pm \alpha$ ), eight factorial experiments (levels \pm 1 ), and six replicates in central point (0) in order to estimate pure error and to assess the lack of fit of the propose models. The response functions measured were total phenolic content and antioxidant activity. When the probability value was below 0.05 , the response variable was subjected to multiple linear regression analysis using RSM, in which the response function $(\mathrm{Y})$ was partitioned into linear, quadratic and interactive components. Data were modelled using Equation (1). The phenolic compounds were extracted from the black rice using citric acid. One gram of ground rice was added to $10 \mathrm{~mL}$ citric acid at different $\mathrm{pH}$. The extraction was performed in the test tube. The tube was then transferred to a water bath at settle temperature and time as demonstrated in Table1. After processing, the extract was filtered (qualitative Whatman \#1 paper). The extract was kept in dark bottle to protect from light and stored immediately at $4{ }^{\circ} \mathrm{C}$ until analysis.

$$
Y=\beta_{0}+\sum_{i=1}^{k} \beta_{i} X_{i}^{2}+\sum \beta_{i j} X_{i}^{2}+\sum_{i>j}^{k} \beta_{i j} X_{i} X_{j}
$$

\subsection{Analysis of total phenolic content}

Total phenolic content was determined using the Folin-Ciocalteu method (Tsia et al., 2007) with slight modifications. About $2 \mathrm{~mL}$ of extract was added with 5 $\mathrm{mL}$ of Folin-Ciocalteu $10 \%(\mathrm{w} / \mathrm{v})$. The solution was stirred for 3 mins and $2 \mathrm{~mL}$ of a $7.5 \% \mathrm{Na}_{2} \mathrm{CO}_{3}$ solution $(\mathrm{w} / \mathrm{v})$ was then mixed and wrapped with parafilm. The solution was left at ambient temperature for 60 mins. The absorbance was recorded at $765 \mathrm{~nm}$ using a spectrophotometer (Helios UUA-161514, Thermo Scientific, USA). The total phenolic content (TPC) was determined from the standard curve of gallic acid. The results were expressed in $\mathrm{mg}$ of gallic acid equivalents per gram dry weight sample (mg GAEg $\left.{ }^{-1} \mathrm{DW}\right)$.

\subsection{Determination of antioxidant activity}

The radical scavenging activity of the extract was measured using the stable radical 2, 2 -diphenyl-1picrylhydrazyl (DPPH) in accordance with Martin et al. (2012). Briefly, $2 \mathrm{~mL}$ of extract was mixed with $2 \mathrm{~mL}$ of methanolic solution of $0.2 \mathrm{mM}$ DPPH. The control was obtained without extract. The mixture was vortexed vigorously and left for 30 mins at room temperature in the dark. The bleaching rate of a stable DPPH was monitored at a characteristic wavelength in the presence of the sample using a spectrophotometer (Helios UUA161514, Thermo Scientific, USA). In its radical form, DPPH absorbs at $517 \mathrm{~nm}$ but, upon reduction by an antioxidant or a radical compound, its absorption decreases. The percentage inhibition values (I) were calculated as given in Equation (2) López-de-Dicastillo et al. (2012).

$$
\mathrm{I}(\%)=\left[\left(\mathrm{abs}_{\text {control }}-\mathrm{abs}_{\text {sample }}\right) / \mathrm{abs} \mathrm{control}\right] \times 100
$$

\section{Results and discussion}

\subsection{Total phenolic content and antioxidant activity}

The experimental design presented twenty combinations as tabulated in Table 1. The three factors tested in this study were extraction temperature, extraction time, and $\mathrm{pH}$. The response variables were the total phenolic content and antioxidant activity. For, Leum Pua, the total phenolic content ranged from 0.3067 to $0.3398 \mathrm{mg} \mathrm{GAE} \mathrm{g}^{-1} \mathrm{DW}$ and DPPH inhibition ranged from 80.08 to $88.52 \%$. The highest total phenolic content was $0.3398 \mathrm{mg} \mathrm{GAE} \mathrm{g}{ }^{-1} \mathrm{DW}\left(75^{\circ} \mathrm{C}, 80\right.$ mins and $\left.\mathrm{pH} 2\right)$ and DPPH inhibition was $88.52 \%\left(75^{\circ} \mathrm{C}, 40 \mathrm{mins}\right.$ and $\mathrm{pH} 2$ ); meanwhile, the lowest total phenolic content was $0.3067 \mathrm{mg} \mathrm{GAE} \mathrm{g}^{-1} \mathrm{DW}\left(70^{\circ} \mathrm{C}, 60 \mathrm{~min}\right.$ and $\left.\mathrm{pH} 3\right)$ and DPPH inhibition was $80.08 \%\left(65^{\circ} \mathrm{C}, 80\right.$ mins and $\left.\mathrm{pH} 4\right)$. For, Doi Saket, the total phenolic content ranged from 0.2351 to $0.2614 \mathrm{mg} \mathrm{GAE} \mathrm{g}^{-1}$ DW and DPPH inhibition ranged from 49.55 to $73.33 \%$. The highest total phenolic content was $0.2614 \mathrm{mg} \mathrm{GAE} \mathrm{g}^{-1} \mathrm{DW}\left(70^{\circ} \mathrm{C}, 60\right.$ mins and $\mathrm{pH} 1.3)$ and $\mathrm{DPPH}$ inhibition was $73.33 \%\left(65^{\circ} \mathrm{C}, 80\right.$ mins and $\mathrm{pH} 2$ ); meanwhile, the lowest total phenolic content was $0.2351 \mathrm{mg} \mathrm{GAE} \mathrm{g}^{-1} \mathrm{DW}\left(75^{\circ} \mathrm{C}, 80 \mathrm{~min}\right.$ and $\mathrm{pH} 4)$ and DPPH inhibition was $49.55 \%\left(70^{\circ} \mathrm{C}, 60 \mathrm{mins}\right.$ and $\mathrm{pH} 3$ ). For, Phayao, the total phenolic content ranged 
Table 1. The responses of the parameters used in central composite design

\begin{tabular}{|c|c|c|c|c|c|c|c|c|c|}
\hline \multirow{3}{*}{ Trials } & \multicolumn{3}{|c|}{ Actual levels (Coded levels) } & \multicolumn{6}{|c|}{ Responses } \\
\hline & $\mathrm{X}_{1}$ & $\mathrm{X}_{2}$ & $\mathrm{X}_{3}$ & \multicolumn{2}{|c|}{ Leum Pua } & \multicolumn{2}{|c|}{ Doi Saket } & \multicolumn{2}{|c|}{ Phayao } \\
\hline & Temp $\left({ }^{\circ} \mathrm{C}\right)$ & Time $(\mathrm{min})$ & $\mathrm{pH}$ & TPC & DPPH & TPC & DPPH & TPC & DPPH \\
\hline 1 & $65(-1)$ & $40(-1)$ & $2(-1)$ & $0.3205 \pm 0.00$ & $85.09 \pm 0.00$ & $0.2358 \pm 0.00$ & $62.33 \pm 0.20$ & $0.2455 \pm 0.00$ & $74.40 \pm 0.24$ \\
\hline 2 & $65(-1)$ & $40(-1)$ & $4(+1)$ & $0.3087 \pm 0.00$ & $85.36 \pm 0.06$ & $0.2429 \pm 0.00$ & $69.74 \pm 0.06$ & $0.2399 \pm 0.00$ & $65.72 \pm 0.06$ \\
\hline 3 & $65(-1)$ & $80(+1)$ & $2(-1)$ & $0.3287 \pm 0.00$ & $84.22 \pm 0.06$ & $0.2409 \pm 0.00$ & $73.33 \pm 0.15$ & $0.2490 \pm 0.00$ & $75.27 \pm 0.19$ \\
\hline 4 & $65(-1)$ & $80(+1)$ & $4(+1)$ & $0.3192 \pm 0.00$ & $80.08 \pm 0.06$ & $0.2375 \pm 0.00$ & $72.23 \pm 0.06$ & $0.2348 \pm 0.00$ & $71.40 \pm 0.28$ \\
\hline 5 & $75(+1)$ & $40(-1)$ & $2(-1)$ & $0.3336 \pm 0.00$ & $88.52 \pm 0.10$ & $0.2527 \pm 0.00$ & $66.55 \pm 0.24$ & $0.2534 \pm 0.00$ & $63.71 \pm 0.30$ \\
\hline 6 & $75(+1)$ & $40(-1)$ & $4(+1)$ & $0.3229 \pm 0.00$ & $84.89 \pm 0.06$ & $0.2484 \pm 0.00$ & $63.12 \pm 0.15$ & $0.2410 \pm 0.00$ & $61.10 \pm 0.11$ \\
\hline 7 & $75(+1)$ & $80(+1)$ & $2(-1)$ & $0.3398 \pm 0.00$ & $84.18 \pm 0.06$ & $0.2586 \pm 0.00$ & $67.77 \pm 0.20$ & $0.2588 \pm 0.00$ & $63.63 \pm 0.06$ \\
\hline 8 & $75(+1)$ & $80(+1)$ & $4(+1)$ & $0.3114 \pm 0.00$ & $82.92 \pm 0.20$ & $0.2351 \pm 0.00$ & $62.80 \pm 0.06$ & $0.2419 \pm 0.00$ & $59.33 \pm 0.11$ \\
\hline 9 & $61.5(-\alpha)$ & $60(0)$ & $3(0)$ & $0.3195 \pm 0.00$ & $80.43 \pm 0.11$ & $0.2453 \pm 0.00$ & $70.97 \pm 0.06$ & $0.2480 \pm 0.00$ & $69.63 \pm 0.11$ \\
\hline 10 & $78.4(+\alpha)$ & $60(0)$ & $3(0)$ & $0.3334 \pm 0.00$ & $85.52 \pm 0.06$ & $0.2385 \pm 0.00$ & $72.15 \pm 0.15$ & $0.2521 \pm 0.00$ & $60.36 \pm 0.10$ \\
\hline 11 & $70(0)$ & $26.3(-\alpha)$ & $3(0)$ & $0.3101 \pm 0.00$ & $85.33 \pm 0.26$ & $0.2516 \pm 0.00$ & $61.74 \pm 0.11$ & $0.2383 \pm 0.00$ & $58.82 \pm 0.17$ \\
\hline 12 & $70(0)$ & $93.6(+\alpha)$ & $3(0)$ & $0.3389 \pm 0.00$ & $87.18 \pm 0.06$ & $0.2569 \pm 0.00$ & $49.66 \pm 0.06$ & $0.2521 \pm 0.00$ & $56.45 \pm 0.10$ \\
\hline 13 & $70(0)$ & $60(0)$ & $1.3(-\alpha)$ & $0.3785 \pm 0.00$ & $84.06 \pm 0.06$ & $0.2614 \pm 0.00$ & $68.17 \pm 0.19$ & $0.2672 \pm 0.00$ & $66.55 \pm 0.06$ \\
\hline 14 & $70(0)$ & $60(0)$ & $4.6(+\alpha)$ & $0.3070 \pm 0.00$ & $82.56 \pm 0.15$ & $0.2392 \pm 0.00$ & $50.84 \pm 0.28$ & $0.2455 \pm 0.00$ & $61.66 \pm 0.33$ \\
\hline 15 & $70(0)$ & $60(0)$ & $3(0)$ & $0.3077 \pm 0.00$ & $80.51 \pm 0.06$ & $0.2570 \pm 0.00$ & $49.82 \pm 0.00$ & $0.2505 \pm 0.00$ & $60.39 \pm 0.06$ \\
\hline 16 & $70(0)$ & $60(0)$ & $3(0)$ & $0.3067 \pm 0.00$ & $80.83 \pm 0.10$ & $0.2585 \pm 0.00$ & $49.55 \pm 0.11$ & $0.2499 \pm 0.00$ & $60.55 \pm 0.15$ \\
\hline 17 & $70(0)$ & $60(0)$ & $3(0)$ & $0.3067 \pm 0.00$ & $80.71 \pm 0.17$ & $0.2576 \pm 0.00$ & $49.70 \pm 0.00$ & $0.2494 \pm 0.00$ & $60.87 \pm 0.06$ \\
\hline 18 & $70(0)$ & $60(0)$ & $3(0)$ & $0.3097 \pm 0.00$ & $80.47 \pm 0.10$ & $0.2585 \pm 0.00$ & $49.90 \pm 0.15$ & $0.2499 \pm 0.00$ & $60.83 \pm 0.10$ \\
\hline 19 & $70(0)$ & $60(0)$ & $3(0)$ & $0.3074 \pm 0.00$ & $80.39 \pm 0.06$ & $0.2571 \pm 0.00$ & $49.55 \pm 0.20$ & $0.2499 \pm 0.00$ & $60.75 \pm 0.06$ \\
\hline 20 & $70(0)$ & $60(0)$ & $3(0)$ & $0.3067 \pm 0.00$ & $80.79 \pm 0.06$ & $0.2575 \pm 0.00$ & $49.65 \pm 0.10$ & $0.2504 \pm 0.00$ & $60.28 \pm 0.06$ \\
\hline
\end{tabular}

from 0.2348 to $0.2672 \mathrm{mg} \mathrm{GAE} \mathrm{g}^{-1} \mathrm{DW}$ and $\mathrm{DPPH}$ inhibition ranged from 56.45 to $75.27 \%$. The highest total phenolic content was $0.2672 \mathrm{mg} \mathrm{GAE} \mathrm{g}^{-1} \mathrm{DW}\left(70^{\circ}\right.$ $\mathrm{C}, 60$ mins and $\mathrm{pH} 1.3$ ) and DPPH inhibition was $75.27 \%\left(65^{\circ} \mathrm{C}, 80\right.$ mins and $\left.\mathrm{pH} 2\right)$; meanwhile, the lowest total phenolic content was $0.2348 \mathrm{mg} \mathrm{GAE} \mathrm{g}^{-1}$ DW $\left(65^{\circ} \mathrm{C}, 80\right.$ mins and $\left.\mathrm{pH} 2\right)$ and $\mathrm{DPPH}$ inhibition was $56.45 \%\left(70^{\circ} \mathrm{C}, 93.6\right.$ mins and $\left.\mathrm{pH} 3\right)$. The statistical comparative study on total phenolic content (TPC) and DPPH inhibition of the extract were examined using RSM and the effects of the independent variables to the responses are discussed in the next section.

\subsection{Model selection and verification of total phenolic content and antioxidant activity}

The collected data were analyzed using software Design Expert 12. All the responses were analyzed using analysis of variance (ANOVA) and regression analysis for model fitting to evaluate the significance of the coefficient terms. The results are tabulated in Table 2. A higher value of regression coefficients can be directly translated to a greater effect of the independent variables on the responses (Chen et al., 2014). For Leum Pua, the effect of extraction temperature $\left(\mathrm{X}_{1}\right)$, extraction time $\left(\mathrm{X}_{2}\right)$, using the linear model and the quadratic effect temperature, led to an increase in the phenolic content. The effect of $\mathrm{pH}\left(\mathrm{X}_{3}\right)$ using the linear model, interaction between $\mathrm{X}_{1} \mathrm{X}_{2}, \mathrm{X}_{1} \mathrm{X}_{3}$ and $\mathrm{X}_{2} \mathrm{X}_{3}$, in linear model, tended to significantly decrease in phenolic content. In addition, the effect of temperature $\left(\mathrm{X}_{1}\right)$ also showed an increase in DPPH inhibition. Meanwhile, the other effects tended to decrease DPPH inhibition. The effect of extraction temperature showed a significant and positive effect on increasing the total phenolic content and antioxidant activity. These results are in line with a study by Pedro et al. (2016), where they found that anthocyanins content and total phenolic content increased with increasing extraction temperature. Raising the temperature increases the diffusion coefficient and the solubility of the compounds increases (Cacace and Mazza, 2003; Pedro et al., 2016). For Doi Saket, the effect of extraction temperature $\left(\mathrm{X}_{1}\right)$, and extraction time $\left(\mathrm{X}_{2}\right)$, using the linear model, led to an increase in the phenolic content. Meanwhile, the other effects showed the decrease DPPH inhibition but the effect of extraction temperature $\mathrm{X}_{1}$, $\mathrm{X}_{1}^{2}$, led to decrease of DPPH inhibition. For Phayao, the effect of extraction temperature $\left(\mathrm{X}_{1}\right)$ showed positively increase on phenolic content but decrease in DPPH inhibition. The effect of extraction time $\left(\mathrm{X}_{2}\right)$ presented in both total phenolic content and DPPH inhibition. Whereas, the effect of $\mathrm{pH}$ led to a decrease in both total phenolic content and DPPH inhibition. The effect of $\mathrm{pH}$ showed negative on increasing the total phenolic content and DPPH inhibition in all varieties. Normally, acidified organic solvents are suitable solutions for extraction of the phenolic compound like anthocyanin from plant materials (Naczk and Shahidi, 2006) due to acidified solvent systems can destroy the cell membrane of plant materials and anthocyanin is then dissolved. Therefore, increasing in $\mathrm{pH}$ of solvent (or lower acidity) decreases the ability of the solvent to destroy cell membrane then resulting negative effect on extraction. In addition, 
extracted anthocyanins are most stable at low $\mathrm{pH}$ which is a strong acidic solution ( $\mathrm{pH}$ less than 3 ) and are relatively unstable to a weak acidic solution to neutral pH values of several foods (Cabrita et al., 2000).

Table 2. Regression coefficients for response variables

\begin{tabular}{|c|c|c|c|c|}
\hline \multirow[b]{2}{*}{ Factor } & \multicolumn{2}{|c|}{ TPC } & \multicolumn{2}{|c|}{ DPPH } \\
\hline & $\begin{array}{c}\text { Coefficient } \\
\text { estimate }\end{array}$ & Probability & $\begin{array}{c}\text { Coefficient } \\
\text { estimate }\end{array}$ & Probability \\
\hline \multicolumn{5}{|l|}{ Lеит Риа } \\
\hline Intercept & 0.3078 & - & 80.61 & - \\
\hline $\mathrm{X}_{1}$-temp & 0.0034 & 0.2707 & 1.05 & 0.0318 \\
\hline $\mathrm{X}_{2}$-time & 0.0037 & 0.2291 & -0.6833 & 0.1352 \\
\hline $\mathrm{X}_{3}-\mathrm{pH}$ & -0.0127 & 0.0015 & -0.8262 & 0.0778 \\
\hline $\mathrm{X}_{1} \mathrm{X}_{2}$ & -0.0022 & 0.5818 & -0.02 & 0.9717 \\
\hline $\mathrm{X}_{1} \mathrm{X}_{3}$ & -0.0037 & 0.3593 & -0.1275 & 0.8212 \\
\hline $\mathrm{X}_{2} \mathrm{X}_{3}$ & -0.0028 & 0.4882 & -0.255 & 0.6525 \\
\hline $\mathrm{X}_{1}^{2}$ & 0.005 & 0.111 & 0.8377 & 0.0679 \\
\hline $\mathrm{X}_{2}^{2}$ & 0.0043 & 0.1627 & 2 & 0.0006 \\
\hline $\mathrm{X}_{3}^{2}$ & 0.0107 & 0.036 & 0.9561 & 0.0416 \\
\hline \multicolumn{5}{|l|}{ Doi Saket } \\
\hline Intercept & 0.258 & - & 49.63 & - \\
\hline $\mathrm{X}_{1}$-temp & 0.0023 & 0.1631 & -1.13 & 0.34 \\
\hline $\mathrm{X}_{2}$-time & 0.0005 & 0.7574 & -0.4339 & 0.708 \\
\hline $\mathrm{X}_{3}-\mathrm{pH}$ & -0.0049 & 0.0101 & -1.35 & 0.2569 \\
\hline $\mathrm{X}_{1} \mathrm{X}_{2}$ & -0.0015 & 0.4653 & -1.57 & 0.3098 \\
\hline $\mathrm{X}_{1} \mathrm{X}_{3}$ & -0.0033 & 0.1378 & -1.84 & 0.2397 \\
\hline $\mathrm{X}_{2} \mathrm{X}_{3}$ & -0.003 & 0.1637 & -1.26 & 0.4131 \\
\hline $\mathrm{X}_{1}^{2}$ & -0.0067 & 0.0013 & 8.33 & $<0.0001$ \\
\hline $\mathrm{X}_{2}^{2}$ & -0.0023 & 0.1584 & 2.72 & 0.0324 \\
\hline $\mathrm{X}_{3}^{2}$ & -0.0037 & 0.0343 & 5.41 & 0.0006 \\
\hline \multicolumn{5}{|l|}{ Phayao } \\
\hline Intercept & 0.2502 & - & 60.44 & - \\
\hline $\mathrm{X}_{1}$-temp & 0.0024 & 0.0389 & -4 & 0.0007 \\
\hline $\mathrm{X}_{2}$-time & 0.002 & 0.0733 & 0.0523 & 0.9508 \\
\hline $\mathrm{X}_{3}-\mathrm{pH}$ & -0.0063 & 0.0001 & -2.03 & 0.0341 \\
\hline $\mathrm{X}_{1} \mathrm{X}_{2}$ & 0.001 & 0.4778 & -1.05 & 0.3538 \\
\hline $\mathrm{X}_{1} \mathrm{X}_{3}$ & -0.0012 & 0.3922 & 0.705 & 0.5285 \\
\hline $\mathrm{X}_{2} \mathrm{X}_{3}$ & -0.0016 & 0.2461 & 0.39 & 0.7255 \\
\hline $\mathrm{X}_{1}^{2}$ & -0.001 & 0.317 & 2.5 & 0.0111 \\
\hline $\mathrm{X}_{2}^{2}$ & -0.0027 & 0.0192 & -0.0981 & 0.9054 \\
\hline $\mathrm{X}_{3}^{2}$ & 0.0012 & 0.2567 & 2.19 & 0.0215 \\
\hline
\end{tabular}

The estimated models built for the phenolic content and DPPH inhibition methods are represented in terms of the coded values. Where $\mathrm{Y}$ is the predicted response; $\mathrm{X}_{1}$ is extraction temperature; $\mathrm{X}_{2}$ is extraction time; and $\mathrm{X}_{3}$ is $\mathrm{pH}$ value. For phenolic content of Leum Pua, Doi Saket and Phayao the model equation are as follows:

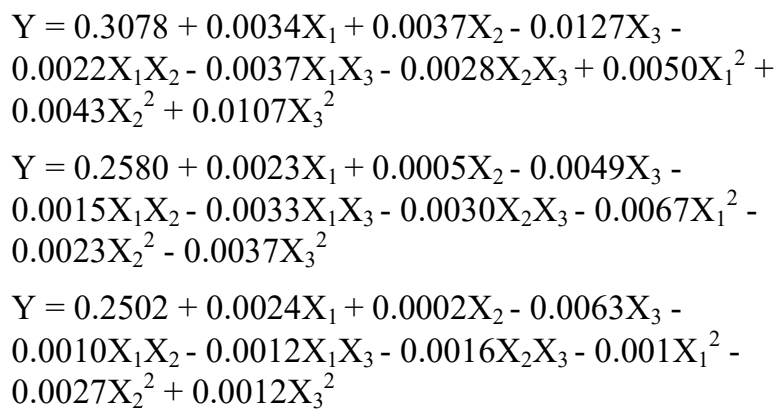

For DPPH inhibition of Leum Pua, Doi Saket and Phayao the model equation are as follows:

$$
\begin{aligned}
& Y=80.61+1.05 \mathrm{X}_{1}-0.6833 \mathrm{X}_{2}-0.8262 \mathrm{X}_{3}-0.02 \mathrm{X}_{1} \mathrm{X}_{2}- \\
& 0.1275 \mathrm{X}_{1} \mathrm{X}_{3}-0.255 \mathrm{X}_{2} \mathrm{X}_{3}+0.8377 \mathrm{X}_{1}^{2}+2.00 \mathrm{X}_{2}^{2}+ \\
& 0.9561 \mathrm{X}_{3}^{2} \\
& \mathrm{Y}=49.63-1.13 \mathrm{X}_{1}-0.4339 \mathrm{X}_{2}-1.35 \mathrm{X}_{3}-1.57 \mathrm{X}_{1} \mathrm{X}_{2}- \\
& 1.84 \mathrm{X}_{1} \mathrm{X}_{3}-1.26 \mathrm{X}_{2} \mathrm{X}_{3}+8.33 \mathrm{X}_{1}^{2}+2.72 \mathrm{X}_{2}^{2}+5.41 \mathrm{X}_{3}^{2} \\
& \mathrm{Y}=60.44-4.00 \mathrm{X}_{1}+0.0523 \mathrm{X}_{2}-2.03 \mathrm{X}_{3}-1.05 \mathrm{X}_{1} \mathrm{X}_{2}+ \\
& 0.705 \mathrm{X}_{1} \mathrm{X}_{3}+0.39 \mathrm{X}_{2} \mathrm{X}_{3}+2.50 \mathrm{X}_{1}^{2}-0.0981 \mathrm{X}_{2}^{2}+2.19 \mathrm{X}_{3}^{2}
\end{aligned}
$$

The regression models of total phenolic content were significant $(\mathrm{p} \leq 0.05)$ and determination coefficients values were $0.8028,0.8089$, and 0.8603 of Leum Pua, Doi Saket, and Phayao, respectively. The regression models of DPPH inhibition were significant $(\mathrm{p} \leq 0.05)$ and determination coefficients values were $0.8084,0.8928$, and 0.8243 of Leum Pua, Doi Saket, and Phayao, respectively.

\subsection{Analysis of response surfaces}

The contour plots of the combined effects of the independent variables of extraction temperature, extraction time, and $\mathrm{pH}$ on DPPH inhibition is shown in Figure 1. In this study, contour plots were obtained by keeping one of the variables constants at a zero level while varying the other two variables.

Figure 1 demonstrates that extraction temperature showed a positive effect on increasing the antioxidant activity of the extract from Leum Pua (Figure 1A) but decreased antioxidant activity of the extract from Phayao (Figure 1C). Moreover, the result also presented the negative effect of extraction time and $\mathrm{pH}$ on antioxidant activity. Generally, raising the temperature increases the diffusion coefficient and the solubility of the compounds increases (Cacace and Mazza, 2003; Pedro et al., 2016). However, temperature above $50^{\circ} \mathrm{C}$ may degrade anthocyanins (Cacae and Mazza, 2003), therefore, the antioxidant activity of extract from some varieties declined. The polarity of solvent was one of the most important factors that affect to extract antioxidant bioactive compounds, particularly in anthocyanin content. At low $\mathrm{pH}$ of extraction, the solvent can protect the oxidation of phenolic compounds and it can soluble and stabilize anthocyanins contents (Ruenroengklin et al., 2008).

\subsection{Optimization of the experiments}

Response surface methodology (RSM) was used to optimize the conditions for the extraction of bioactive compound from black glutinous rice. The design of the experiment was carried out using Design Expert 12. In the optimization selection, there were three factors for a 
(A)

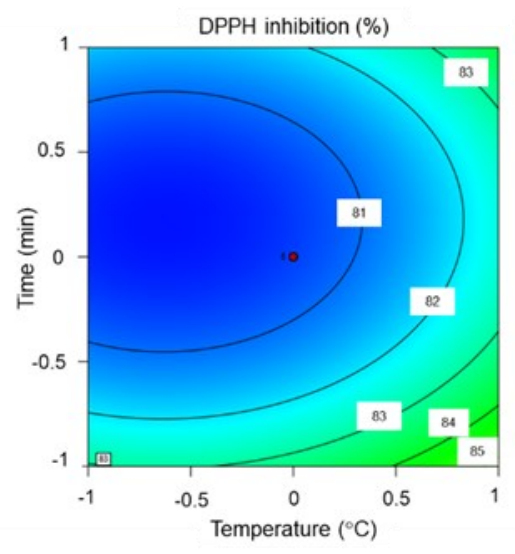

(B)

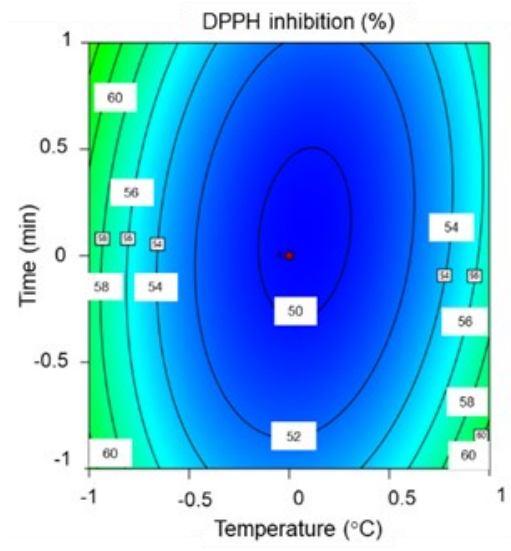

(C)

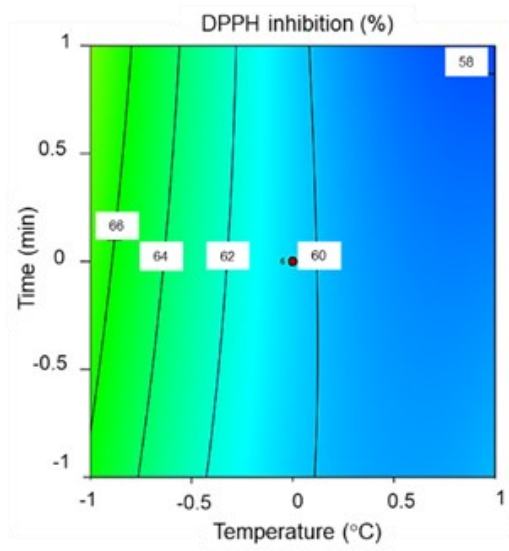

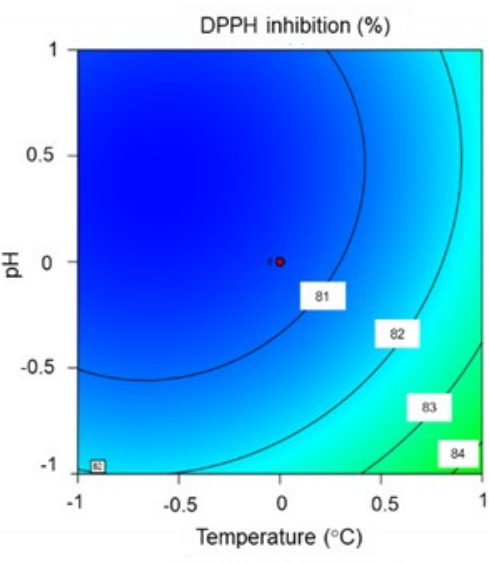
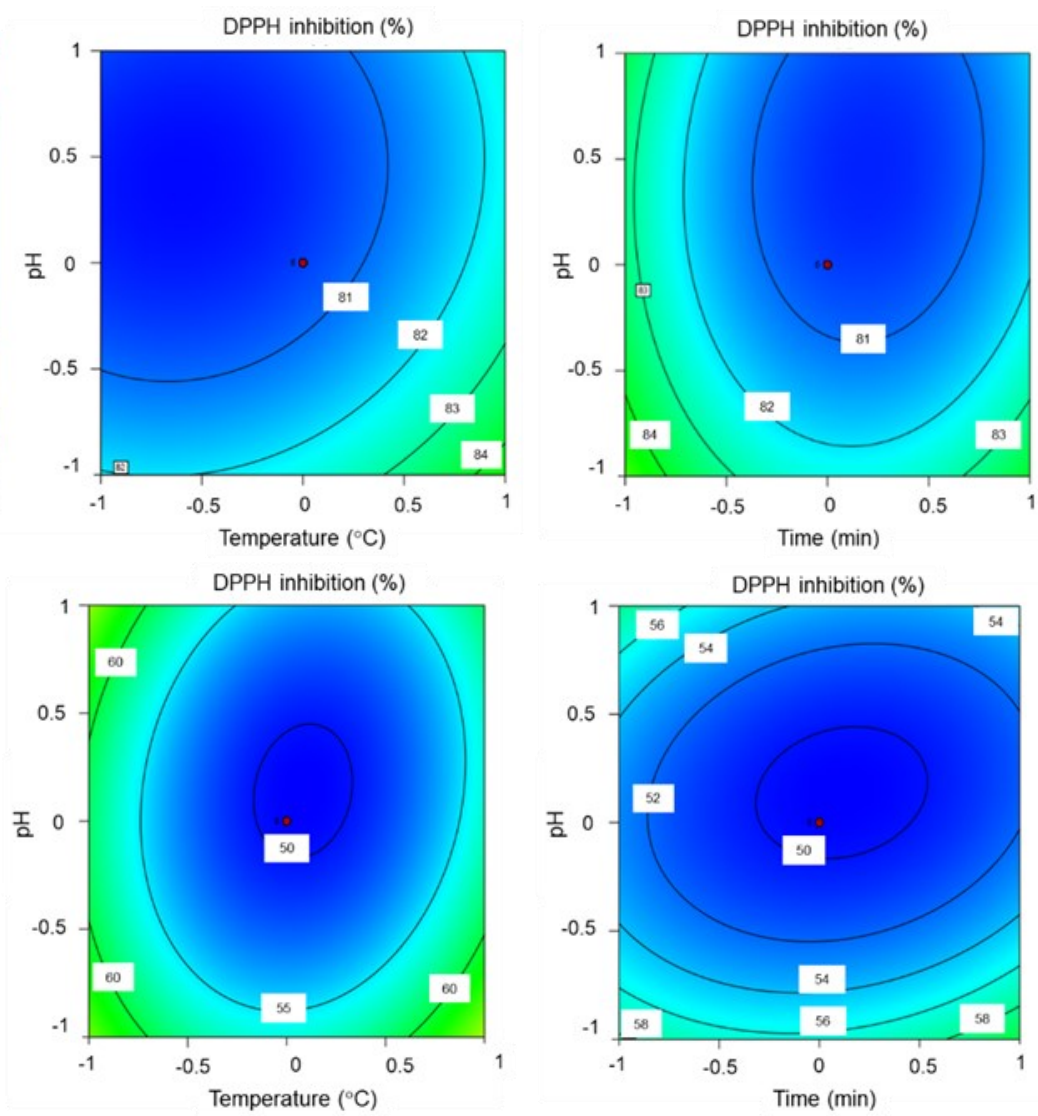

DPPH inhibition (\%)
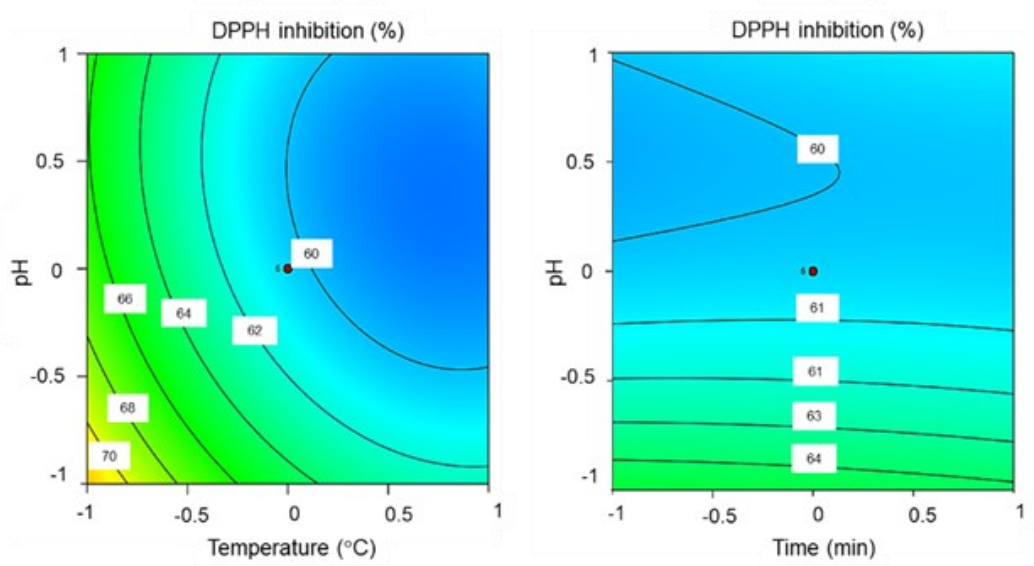

Figure 1. Response surfaces plots of the combined effects of the independent variables on DPPH inhibition of extract from (A) Leum Pua; (B) Doi Saket and (C) Phayao

goal to construct desirability indices: extraction temperature, extraction time, and $\mathrm{pH}$ value. The goal for both total phenolic content and DPPH inhibition was the highest values from the experimental results obtained. The optimization of the responses is displayed in Table 3 . The acceptable values of the desirability function were the values close to one $(100 \%)$.

In this study, the antioxidant property of phenolic compound extracted from black glutinous rice including Leum Pua, Doi Saket and Phayao compromised with optimum conditions as shown in Table 3 had 100, 98.50, and $94.10 \%$ desirability, respectively.

In addition, this study demonstrated that under the optimum condition the highest responses of total phenolic content and DPPH inhibition were found in Leum Pua extract compared to Doi Saket and Phayao.
Similarly, Pramai and Jiamyangyuen (2016) studied the phenolic contents and antioxidant activity thirteen varieties of black rice and reported that Leum Pua presented a higher content of total phenolic and antioxidant activity in term of DPPH scavenging ability than Doi Saket and Phayao. The colour of extract from black glutinous rice under optimum condition present in Figure 2. The result showed the dark red of Leum Pua extract and the bright red of Doi Saket and Phayao extract. It could be related to a higher amount of anthocyanin in Leum Pua. In general, the anthocyanins derive from the flavylium cation and contain one or more hydroxyl substituents including other functional groups such as sugars (Pedro et al., 2016). The presence of hydroxyl groups contributes antioxidant properties by donating hydrogen atoms to reactive species then form stable products. Thus, the higher the anthocyanin 
Table 3. Optimum condition of the independent variables and the responses of the extraction of bioactive compound from black glutinous rice

\begin{tabular}{|c|c|c|c|c|c|c|}
\hline \multirow[b]{2}{*}{ Cultivar } & \multirow[b]{2}{*}{$\begin{array}{c}\text { Temperature } \\
\left({ }^{\circ} \mathrm{C}\right)\end{array}$} & \multirow[b]{2}{*}{ Time (min) } & \multirow[b]{2}{*}{$\mathrm{pH}$} & \multicolumn{2}{|c|}{ Predicted values } & \multirow[b]{2}{*}{ Desirability } \\
\hline & & & & $\begin{array}{c}\text { TPC } \\
\left(\mathrm{GAE} \mathrm{g}^{-1} \mathrm{DW}\right)\end{array}$ & $\begin{array}{c}\text { DPPH inhibition } \\
(\%)\end{array}$ & \\
\hline Leum Pua & 72 & 91 & 1.44 & 0.3814 & 89.36 & 1 \\
\hline Doi Saket & 72.5 & 83 & 1.39 & 0.2607 & 73.33 & 0.985 \\
\hline Phayao & 66.3 & 75 & 1.32 & 0.2617 & 75.27 & 0.941 \\
\hline
\end{tabular}

content, the higher the antioxidant activity (Zhang et al.,

2015; Pedro et al., 2016).
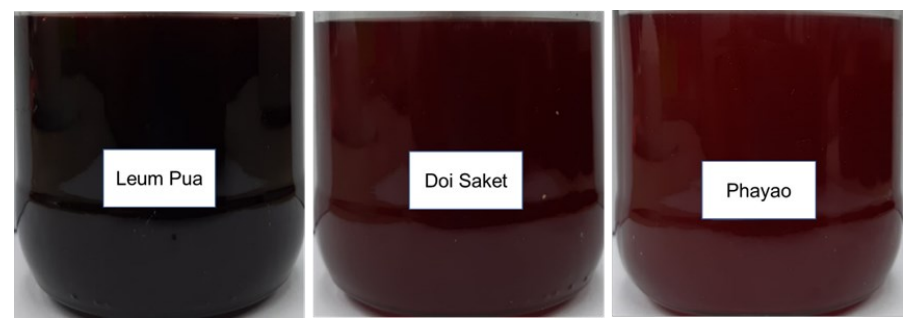

Figure 2. The extract from three varieties of black glutinous rice under the optimum condition

\section{Conclusion}

The effect of extraction temperature, time and $\mathrm{pH}$ on total phenolic content and antioxidant activity of the extract from three black glutinous rice including Leum Pua, Doi Saket and Phayao was investigated. The extraction temperature showed the positive effect on total phenolic content of the rice extracted from three varieties but provided negative effect on antioxidant activity of the extract of Phayao. The similar results were found in time affecting. The extraction time presented the positive effect on total phenolic content but a negative effect on antioxidant of the extract of Leum Pua and Doi Saket. Meanwhile, $\mathrm{pH}$ values provide a negative effect on both total phenolic content and antioxidant activity, Therefore, the optimum condition was studied by response surface methodology (RSM). The selected optimum conditions were $72^{\circ} \mathrm{C}, 91 \mathrm{mins}$ at $\mathrm{pH} 1.44$ for Leum Pua, $72.5^{\circ} \mathrm{C}, 83$ mins at $\mathrm{pH} 1.39$ for Doi Saket, and $66.3^{\circ} \mathrm{C}, 75$ mins at $\mathrm{pH} 1.32$ for Phayao. Under the optimum condition, total phenolic content and percentage of inhibition of DPPH free radical of extract from Leum Pua, Doi Saket and Phayao were $0.3814 \mathrm{mg}$ GAE $\mathrm{g}^{-1}$ DW with $89.37 \%$ DPPH inhibition, $0.2607 \mathrm{mg}$ GAE $\mathrm{g}^{-1}$ DW with $73.33 \%$ DPPH inhibition, and 0.2617 mg GAE $\mathrm{g}^{-1}$ DW with $75.27 \%$ DPPH inhibition, respectively. From the result can be concluded that under the optimum condition of extraction, Leum Pua glutinous black rice provided the highest amount of total phenolic content and showed the highest efficiency compared with other varieties. The extraction of the bioactive compound using organic acid like citric acid under optimum condition can be desirable for non-toxic process and safety for application in food products and others.

\section{Acknowledgement}

The authors would like to acknowledge the financial support provided by Maejo University under research grant of the National Research Council of Thailand and the Southeast Asian Regional Center for Graduate Study and Research in Agriculture (SEARCA).

\section{References}

Bae, I.Y, An, J.S., Oh, I.K. and Lee, H.G. (2017). Optimized preparation of anthocyanin-rich extract from black rice and its effects on in vitro digestibility. Food Science and Biotechnology, 26 (5), 1415-1422. https://doi.org/10.1007/s10068-0170188-x

Cabrita, L., Fossen, T. and Andersen, Ø.M. (2000). Colour and stability of the six common anthocyanidin 3-glucosides in aqueous solutions. Food Chemistry, 68(1), 101-107. https:// doi.org/10.1016/S0308-8146(99)00170-3

Cacace, J.E. and Mazza, G. (2003). Optimization of extraction of anthocyanins from black currants with aqueous ethanol. Journal of Food Science, 68(1), 240-248. 2621.2003.tb14146.x

Chen, X.Q., Nagao, N., Itani, T. and Irifune, K. (2012). Anti-oxidative analysis, and identification and quantification of anthocyanin pigments in different coloured rice. Food Chemistry, 135(4), 2783-2788. https://doi.org/10.1016/j.foodchem.2012.06.098

Escribano-Bailón, M.T., Santos-Buelga, C. and RivasGonzalo, J.C. (2004). Review-Anthocyanins in cereals. Journal of Chromatography A, 1054(1-2), 129-141. https://doi.org/10.1016/ j.chroma.2004.08.152

López-de-Dicastillo, C., Gómez-Estaca, J., Catalá ,R., Gavara, R. and Hernández-Muñoz, P. (2012). Active antioxidant packaging films: Development and effect on lipid stability of brined sardines. Food Chemistry, 131(4), 1376-1384. https://doi.org/10.1016/ j.foodchem.2011.10.002

Martins, J.T., Cerqueira, M.A. and Vicente, A.A. (2012). Influence of a-tocopherol on physicochemical properties of chitosan-based films. Food Hydrocolloids, 27(1), 220-227. https:// doi.org/10.1016/j.foodhyd.2011.06.011 
Naczk, M. and Shahidi, F. (2006). Phenolics in cereals, fruits and vegetables: occurrence, extraction and analysis. Journal of Pharmaceutical and Biomedical Analysis, 41(5), 1523-1542. https://doi.org/10.1016/ j.jpba.2006.04.00

Nontasan, S., Moongngarm, A. and Deedseethum, S. (2012). Application of functional colorant prepared from black rice bran in yogurt. APCBEE Procedia, 2, 62-67. https://doi.org/10.1016/ j.apcbee.2012.06.012

Pedro, A.C., Granato, D. and Rosso, N.D. (2016). Extraction of anthocyanins and polyphenols from black rice (Oryza sativa L.) by modeling and assessing their reversibility and stability. Food Chemistry, 191(15), 12-20. https://doi.org/10.1016/ j.foodchem.2015.02.045

Phetpornpaisan, P., Tippayawat, P., Jay, M. and Sutthanut, K. (2014). A local Thai cultivar glutinous black rice bran: A source of functional compounds in immunomodulation, cell viability and collagen synthesis, and matrix metalloproteinase-2 and -9 inhibition. Journal of Functional Foods, 7, 650-661. https://doi.org/10.1016/j.jff.2013.12.020

Pramai, P. and Jiamyangyeun, S. (2016). Chemometric classification of pigmented rice varieties based on antioxidative properties in relation to color. Songklanakarin Journal of Science and Technology, 38(5), 463-472. https://doi.org/10.14456/sjstpsu.2016.62

Ruenroengklin, N., Zhong, J., Duan, X., Yang, B., Li, J. and Jiang, Y. (2008). Effects of various temperatures and $\mathrm{pH}$ values on the extraction yield of phenolics from litchi fruit pericarp tissue and the antioxidant activity of the extracted anthocyanins. International Journal of Molecular Sciences, 9(7), 1333-1341. https://doi.org/10.3390/ijms9071333

Seekhaw, P., Mahatheeranont, S., Sookwong, P., Luangkamin, S., Na Lampang Neonplab, A. and Puangsombat, P. (2018). Phytochemical constituents of Thai dark purple glutinous rice bran extract [Cultivar Leum Pua (Oryza sativa L.)]. Chiang Mai Journal of Science, 45(3), 1383-1395.

Shao, Y., Xu, F., Sun, X., Bao, J. and Beta, T. (2014). Identification and quantification of phenolic acids and anthocyanins as antioxidants in bran, embryo and endosperm of white, red and black rice kernels (Oryza sativa L.). Journal of Cereal Science, 59(2), 211-218. https://doi.org/10.1016/j.jcs.2014.01.004

Tsai, S.-Y., Tsai, H.-L. and Mau, J.-L. (2007). Antioxidant properties of Agaricus blazei, Agrocybe cylindracea, and Boletus edulis. LWT-Food Science and Technology, 40(8), 1392-1402. https:// doi.org/10.1016/j.lwt.2006.10.001
Zhang, H., Shao, S., Bao, J. and Beta, T. (2015). Phenolic compounds and antioxidant properties of breeding lines between the white and black rice. Food Chemistry, 172(1), 630-639. https:// doi.org/10.1016/j.foodchem.2014.09.118 